\title{
Agôn
}

Revue des arts de la scène

Critiques | Saison 2014-2015

\section{Wycinka Holzfällen (Des arbres à abattre), texte de Thomas Bernhard, mise en scène Krystian Lupa}

Du théâtre par sédimentation

\section{Caroline Châtelet}

\section{(2) OpenEdition}

Journals

Édition électronique

URL : http://journals.openedition.org/agon/3258

DOI : 10.4000 /agon.3258

ISSN : 1961-8581

Éditeur

Association Agôn

Référence électronique

Caroline Châtelet, « Wycinka Holzfällen (Des arbres à abattre), texte de Thomas Bernhard, mise en scène Krystian Lupa », Agôn [En ligne], Critiques, mis en ligne le 30 juillet 2015, consulté le 23 septembre 2020. URL : http://journals.openedition.org/agon/3258 ; DOl : https://doi.org/10.4000/agon.3258

Ce document a été généré automatiquement le 23 septembre 2020.

Association Agôn et les auteurs des articles 


\section{Wycinka Holzfällen (Des arbres à abattre), texte de Thomas Bernhard, mise en scène Krystian Lupa}

Du théâtre par sédimentation

\section{Caroline Châtelet}

\section{RÉFÉRENCE}

Wycinka Holzfällen (Des arbres à abattre), texte de Thomas Bernard, mise en scène de Krystian Lupa - Festival d'Avignon, La FabricA - du 4 au 8 juillet http://www.festival-avignon.com

1 On ne dira jamais assez à quel point la traversée d'un festival complique autant qu'amplifie la réception des spectacles. Trop de propositions, pas assez de temps, la fatigue qui s'accumule d'un côté, les résonances, les récurrences de parti pris, de propos, d'images ou de musiques de l'autre. Et puis, au milieu de ce tumulte, soudain surgit une œuvre. Une. Celle qui pourrait sur le champ tout vous faire lâcher. Faire les valises, repartir. Mettre fin à la frénésie dispendieuse et vaine. Juste pour laisser à ce travail le temps de se déposer, se donner les moyens de le digérer, de l'assimiler. Cette œuvre a eu lieu, cette année à Avignon, avec l'adaptation par Krystian Lupa du texte de Thomas Bernhard Des arbres à abattre, aussi brillamment interprété qu'adapté. Ce n'est pas la première fois que Lupa monte Bernhard, cela fait même plusieurs années que le metteur en scène polonais entretient un dialogue fécond avec l'œuvre de l'auteur autrichien. Il y a eu Perturbation en 2013, Déjeuner chez Wittgenstein en 2004, ou encore Kalkwerk et Extinction en 2003 et 2001.

2 Au sujet de son intérêt pour l'auteur, Lupa confiait notamment «Bernhard m'habite obstinément, sans relâche, et agit en moi mystérieusement " ${ }^{1}$. À vrai dire on ne saurait mieux définir ce que son théâtre produit. Lupa travaillant sur des durées hors-normes (4h30 ici, mais cela peut aller jusqu'à 8 heures comme pour Factory 2, création sur la Factory 
d'Andy Warhol), découvrir son travail passe par une lente imprégnation, une traversée progressive des strates composant chaque spectacle. Dans cette construction par sédimentation, il entremêle les lieux, les périodes historiques comme les propos. À cette image, la scénographie elle-même procède par couches, empilement progressif, déplacement, les espaces s'enchevêtrant et se superposant, travaillant sans cesse la perspective. Dans ce roman, le narrateur, double de Bernhard, raconte ses retrouvailles avec le microcosme bourgeois et culturel viennois le temps d'un enterrement et d'un dîner mondain. Enterrement d'une comédienne ayant vécu en marge des circuits officiels, dîner en l'honneur d'un célèbre acteur du Théâtre national: les deux événements révèlent également avec une ironie grinçante les échecs comme les réussites des membres de cette petite société, membres qui se connaissent depuis trente ans. Ainsi les espaces se révèlent progressivement: d'abord le salon du couple bourgeois où les invités s'installent. Une vitre de verre dépoli les isole du public et rappelle à quel point tous vivent dans un monde étriqué - seul le narrateur Thomas Bernhard demeurant à l'extérieur. Ensuite apparaissent successivement d'autres espaces, présents ou passés, concrets ou projetés en images : la chambre de la défunte Johanna, où la comédienne sombre dans l'alcool ; une église ; l'intégralité du salon où se tient la réception ; une forêt.

Wycinka Holzfällen (Des arbres à abattre). Photographie de plateau

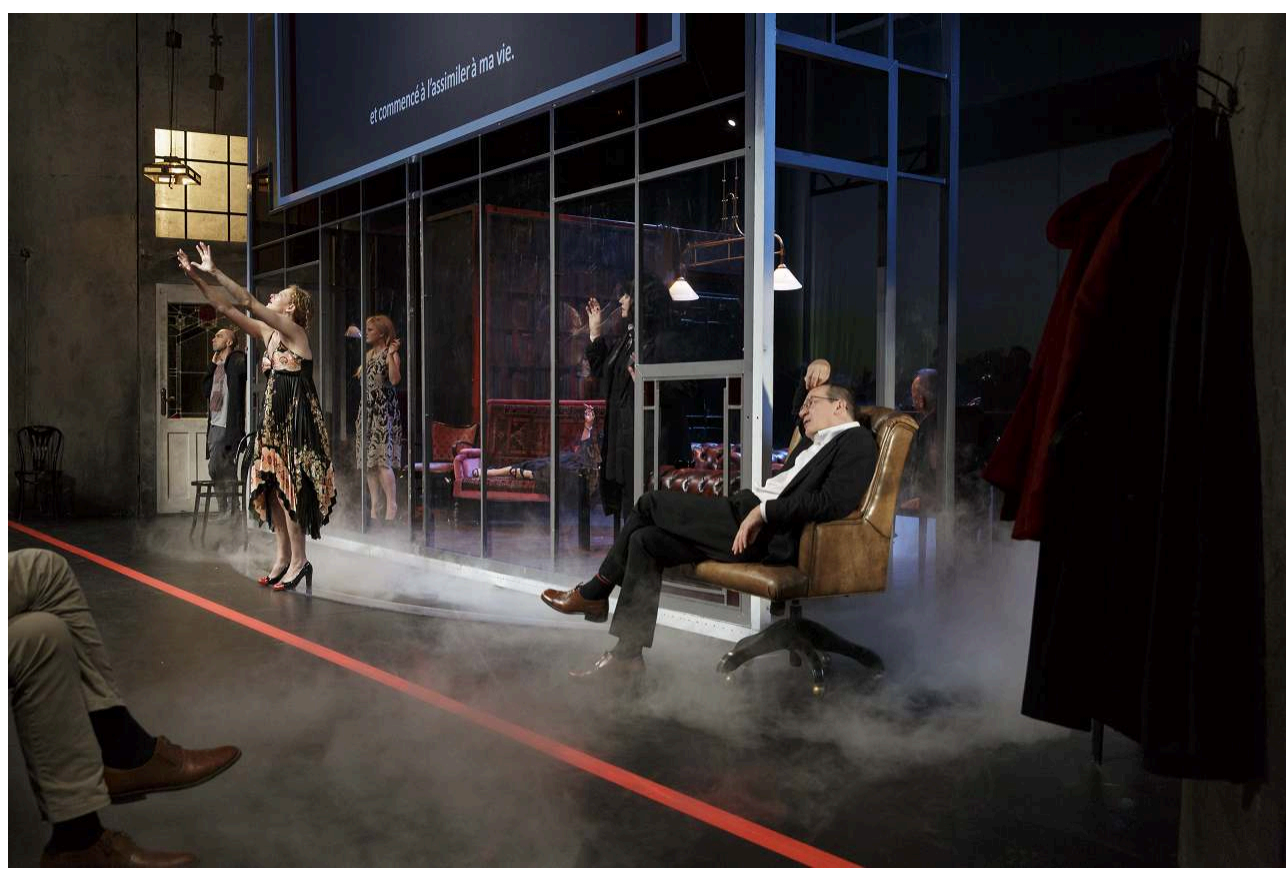

Wycinka Holzfällen (Des arbres à abattre), texte de Thomas Bernard, mise en scène de Krystian Lupa Festival d'Avignon, La FabricA - du 4 au 8 juillet

http://www.festival-avignon.com

(c) Christophe Raynaud de Lage / Festival d'Avignon

La forêt... représentée à deux reprises elle condense aussi la manière Lupa, cette façon d'imbriquer les références, les citations. D'abord lointaine, dense, inquiétante, elle renvoie au Canard sauvage, pièce d'Henrik Ibsen citée en permanence dans le roman. Lieu fantasmatique de l'évasion et d'une tentative d'échapper à la corruption du monde pour Ibsen, elle est une image possible du théâtre, espace d'illusion. Puis, plus proche, à hauteur d'hommes, entourant les personnages, elle désigne la «Forêt, forêt de haute 
futaie, des arbres à abattre » évoquée par le comédien du Théâtre national à la fin du repas. Là, elle devient l'espace pour fuir un monde corrompu, artificiel et fondé sur le simulacre. Ces deux visions de la forêt, du lieu fantasmatique à la pure nature racontent, peut-être, dans leur antinomie les parcours des deux comédiens " célébrés " ce soir-là. À moins qu'elles ne disent, dans l'écart de leur convocation - la première se situant au début du spectacle, la seconde à la fin - les désillusions d'une vie et la difficulté pour les artistes à réaliser l'intransigeance à laquelle ils aspirent.

Le Canard sauvage n'est pas la seule œuvre convoquée par Bernhard: du Chemin de Damas d'August Strindberg au Boléro de Ravel, en passant par Henry Purcell, les références s'entremêlent. Chaque œuvre est l'occasion d'en appeler d'autres et d'activer des problématiques, des tensions. Au cœur de la pièce d'Ibsen comme du récit de Strindberg se trouve celle de la place de l'artiste, question ressassée par le comédien du Théâtre national lors du dîner et qui se déploie dans toute la seconde partie. Déplaçant la puissante charge contre la bourgeoisie viennoise vers l'Europe dans son entier - nous ne sommes plus à Vienne mais dans une quelconque ville européenne - Lupa interroge le monde de l'art et ses compromissions. Ces questions, il les pose autant à lui-même qu'aux acteurs et aux spectateurs. On le saisit dès le début de la seconde partie où le verre dépoli a disparu et les personnages s'adressent directement à la salle, conviant le public à la table des échanges. D'ailleurs, le fait que le metteur en scène ait quitté en 2013 la direction du Stary Teatr de Cracovie pour un autre à Varsovie; et que la majorité des comédiens soient issus de sa nouvelle troupe apporte une autre " couche " de sens à ces interrogations. À l'aune de ce changement, on ne peut qu'entendre différemment la virulente diatribe prononcée par le comédien du Théâtre national contre le système culturel, la collusion entre pouvoir artistique et politique, et la valse de directeurs à la tête de théâtres. Le narrateur Thomas Bernhard étant interprété par Piotr Skiba, acteur fétiche de Krystian Lupa, un glissement s'opère et il devient par la transposition théâtrale le double, l'alter-ego de Lupa. Par son discours, ses interrogations, et sa position sur les côtés de l'avant-scène, voire hors de la zone du théâtre (zone que Lupa délimite pour chaque spectacle, ceinturant le cadre de jeu par une bande rouge), ce personnage-miroir observe, décrit et commente les actions de ce petit monde. Mais - je me répète - il ne s'en exclut pas et plutôt que de rage (comme chez Bernhard), Lupa substitue une critique non dénuée de sentiments. Le dernier dialogue n'énonce d'ailleurs que cela : regagnant le salon, le narrateur renie toutes ses critiques précédentes et délaisse la haine pour la tendresse, produisant par ce geste et ce discours une atmosphère d'une extrême mélancolie.

Alors, pourquoi chef-d'œuvre? Chacun mettra derrière ce qualificatif des sens et définitions divers. Pour ma part, l'œuvre se niche dans la capacité d'un artiste à créer une tension entre un propos et ses obsessions intimes. Dans sa faculté à porter un texte tout en révélant comment il interroge son travail et sa position de créateur. Cela, Lupa le fait dans chacun de ses spectacles: dans Factory 2, le metteur en scène ne reconstituait pas la Factory de Warhol, il créait la sienne, à partir (comme toujours chez lui) d'un patient travail de répétitions et d'improvisations avec ses comédiens. Dans Perturbation, la transposition du texte de Bernhard lui permettait d'interroger les questions de la transmission et du poids de l'histoire (personnelle comme collective). Pour Des arbres à abattre, ce travail est poussé à son acmé et l'intrication entre le texte originel et ce que Lupa en fait, la manière dont il met en jeu sa propre pratique et $y$ inclut ses comédiens, amplifie la puissance de l'œuvre de Bernhard. Dans cette lente 
traversée se dessine des obsessions lancinantes sur le geste créateur, la place de l'artiste dans la société, celle qu'il accepte de prendre comme celle qu'on lui assigne, ses limites comme ses déviances. Un an après un festival d'Avignon parsemé de grèves et d'annulations, et alors que cette édition 2015 s'est déroulée dans une totale atonie politique, ces questions résonnent avec d'autant plus d'acuité.

\section{NOTES}

1. Entretien avec Jean-François Perrier, Dossier de presse du Festival d'Avignon, 2015. 